\title{
LA POLÍTICA DE CONCESIONES A LOS GRUPOS MINEROS DE MÉXICO
}

\author{
Isidro Téllez Ramírez y Aleida Azamar Alonso ${ }^{\text {b }}$
}

Fecha de recepción: 13 de julio de 2020. Fecha de aceptación: 19 de diciembre de 2020.

$$
\text { https://doi.org/10.22201/iiec.20078951e.2021.206.69714 }
$$

\begin{abstract}
Resumen. El objetivo del presente artículo es analizar los cambios políticos, económicos y territoriales que permitieron mejores condiciones para la acumulación del gran capital minero privado en México. Asimismo, se revisan continuidades y contradicciones del proceso durante el periodo 1982-2018. Por medio del análisis documental, estadístico y cartográfico se evidencia que, desde la década de los noventa, los grupos mineros mexicanos son los que dominan la producción minero-metalúrgica. Se concluye que la desincorporación de reservas mineras federales, la privatización de las empresas mineras con participación estatal, los cambios en el marco jurídico y el acaparamiento de concesiones mineras son elementos que favorecieron el actual grado de integración, diversificación e internacionalización de capital alcanzado por estos conglomerados.
\end{abstract}

Palabras clave: grupos mineros; privatización; concesión minera; concentración de capital; despojo.

Clasificación JEL: L11; L13; L72.

\section{The POliCy Of CONCESSIONS TO MINING GROUps IN MeXico}

\begin{abstract}
This article analyzes the political, economic, and territorial changes that enabled conditions more favorable to the accumulation of large private mining capital in Mexico. The article also reviews the continuities and contradictions present in this process during the period 1982-2018. Documentary, statistical, and cartographic analysis reveal that since the 1990s, Mexican mining groups have dominated mining and metallurgical production. It is concluded that the disincorporation of federal mining reserves, the privatization of mining companies with state involvement, the changes in the legal framework, and the monopolization of mining concessions are elements that favored the extent of integration, diversification, and capital internationalization mining companies have attained.
\end{abstract}

Key Words: mining groups; privatization; mining concession; capital concentration; dispossession.

\footnotetext{
${ }^{a}$ Universidad Nacional Autónoma de México (UNAM), Posgrado en Geografía; ${ }^{b}$ Universidad Autónoma Metropolitana-Unidad Xochimilco, Departamento de Producción Económica. Correos electrónicos: isidrotr@gmail.com y gioconda15@gmail.com, respectivamente. La presente investigación se realizó con el apoyo de la DGapa-unam, a través del proyecto papitt "Atlas de la Minería de México", clave IN303417.
} 


\section{INTRODUCCIÓN}

Durante los últimos años, la gran minería en México ha sido objeto de estudio por varios investigadores de disciplinas como la ecología política (Cohen, 2015), la economía (Azamar, 2017; Morales y Téllez, 2016; Paredes et al., 2016), la geografía (Morales, 2002; Sánchez y Casado, 2018) o la antropología (Cortés, 2018; Garibay et al., 2011), entre otras. Esta literatura, por lo general, se centra en los efectos ambientales negativos y la conflictividad social ocasionada por estas compañías, en especial, por los proyectos mineros de capital canadiense emblemáticos. En tanto, los estudios sobre las grandes empresas mexicanas también abordan los impactos ambientales y sociales, pero de manera aislada; es decir, solamente para alguna de las numerosas minas que controlan los grupos mineros de capital privado nacional (Islas, 2017); mientras que los aspectos económicos reciben menor atención, lo que incide en la creencia de que las empresas extranjeras dominan la producción minerometalúrgica nacional (Guevara, 2016).

Contrario a esta última opinión, investigaciones como las realizadas por Delgado Wise y Del Pozo (2001), Morales y Téllez (2016) y Sánchez y Casado (2018) muestran que, si bien la minería mexicana se definía históricamente por la debilidad de los empresarios nacionales, esta situación se invirtió y en la actualidad son algunos oligopolios locales los que dominan la producción minero-metalúrgica de los principales recursos mineros que exporta México. Estos autores señalan que la adopción del modelo económico de corte neoliberal a partir de los años ochenta, así como la reforma y creación de distintas leyes y reglamentos relacionados con dicha actividad económica, son factores determinantes en el vertiginoso crecimiento de las grandes compañías mineras mexicanas, por encima de empresas foráneas como Goldcorp, Pan American Silver, Torex Gold, Agnico Eagle o Alamos Gold.

De esta forma es que este artículo busca contribuir a esta última literatura, mediante la atención de un objetivo doble: por un lado, identificar los cambios políticos, económicos y territoriales que permitieron que el gran capital minero mexicano haya obtenido un mayor nivel de relevancia en el sector minero-metalúrgico nacional y, por otro, analizar continuidades y contradicciones de tal proceso de concentración de capital durante el periodo 1982-2018.

Así, el análisis se centra en los cinco grupos mineros de capital nacional más importantes del país: Grupo México, Industrias Peñoles, Grupo Acerero del Norte, Minera Frisco y Grupo Ferrominero (Compañía Minera Autlán). Se entiende por grupo minero a la compañía central conformada por distintas subsidiarias, integradas vertical y horizontalmente, así como interconecta- 
das por lazos familiares, con una misma estrategia de crecimiento, control y obtención de ganancias (Dos Santos, 2016).

El método que se empleó en esta investigación es mixto, basado fundamentalmente en el análisis de estadísticas oficiales. Las principales fuentes de información empleadas fueron las bases de datos proporcionadas por la Secretaría de Economía y los informes anuales elaborados por las propias empresas. También se recurrió al análisis e interpretación cartográfica de las concesiones mineras mediante el programa QGis, versión 3.4 Madeira, con el objetivo de determinar su localización, distribución y tamaño por grupo minero. Para complementar esta información se consultó el listado de las 500 empresas más importantes de México que realiza la Revista Expansión, así como distintas publicaciones académicas, con el propósito de contextualizar y confrontar los resultados. El aporte de esta investigación es documentar un panorama de los principales cambios, continuidades y contradicciones del gran capital minero mexicano desde una perspectiva espacio-temporal.

El trabajo se integra por cinco apartados, además de la introducción, y está estructurado de la siguiente forma: en la segunda parte se discuten los aspectos conceptuales sobre los que se apoya la crítica de este trabajo; en la tercera se revisa el papel del proceso de desincorporación de las reservas mineras nacionales y de la privatización de las empresas con participación estatal en la formación y consolidación de los grupos mineros mexicanos. En la cuarta se analiza el acaparamiento del subsuelo de estas compañías mediante la concentración de concesiones mineras. En la quinta parte se valora la participación en la producción nacional y el grado de integración, diversificación e internacionalización de capital alcanzado por los cinco grupos mineros, así como su influencia en el desarrollo de la industria nacional. Finalmente, se presentan las conclusiones.

\section{EL DESPOJO PARA LA ACUMULACIÓN DEL CAPITAL MINERO}

La emergencia de operaciones y proyectos mineros en América Latina ha sido abordada, principalmente, desde dos perspectivas teóricas. La primera es la propuesta del extractivismo, planteamiento influenciado por la ecología política y los procesos de reprimarización de las economías dependientes. La segunda es desde la acumulación por desposesión, concepto que recupera los planteamientos de Marx (2003) sobre los mecanismos extraeconómicos que sustentan hasta el día de hoy al capitalismo. 
El extractivismo trata de un concepto recurrido por distintos autores para referirse al estilo de desarrollo caracterizado por la extracción intensiva de grandes volúmenes de recursos, sin procesar o con un procesamiento limitado, que afecta a grandes áreas geográficas, volcado a la exportación, de alto impacto social y ambiental, y de dudosos beneficios para los territorios donde se asienta (Gudynas, 2015). Dentro de los ejemplos clásicos se ubica la actividad minera, así como la extracción de hidrocarburos, la expansión de la ganadería y de los monocultivos de exportación, entre otras actividades que descansan en economías de enclave, casi siempre desconectadas de las economías locales o nacionales (Azamar, 2018; Svampa, 2019).

Respecto a la acumulación por desposesión (o despojo), es un planteamiento propuesto por Harvey (2007) que recupera el concepto de acumulación originaria de Marx (2003), interpretándolo como un proceso de acumulación constituido por numerosas prácticas basadas en medios extraeconómicos que representan la forma predominante de acumulación en el neoliberalismo y una posibilidad de solución a las recurrentes crisis de sobreacumulación de capital (Téllez y Sánchez, 2018). Entre las principales prácticas depredatorias se encuentra la extracción de bienes naturales, el acaparamiento de tierras y bienes comunes, y la privatización de la infraestructura pública (agua, sanidad, telecomunicaciones, transportes e incluso instituciones públicas como universidades) (Harvey, 2007).

Tanto el extractivismo como la acumulación por desposesión son propuestas teóricas que coinciden en que el origen de los problemas derivados de las actividades mineras, en especial de las operaciones a cielo abierto, se sitúan en la adopción del modelo económico neoliberal. Ambos resaltan el hecho de que el Estado ocupa un papel crucial en la consecución de esta actividad, no sólo para forzar la adopción de dispositivos institucionales capitalistas, sino también para adquirir y privatizar bienes como cimiento original para la acumulación de capital a favor de ciertas clases o fracciones de éstas (Harvey, 2007).

Sin embargo, el extractivismo es una propuesta teórica que tiene limitantes para explicar la realidad de países como México. En primer lugar porque en su conceptualización la minería no figura como una industria, pues considera que se trata de una actividad que sólo se remite a la extracción y exportación de minerales sin un procesamiento propio de manufactura (Gudynas, 2015). Este supuesto no corresponde con el grado de integración vertical alcanzado por los grandes grupos mineros mexicanos, y que es objeto de esta investigación. Como se expone en los siguientes apartados, las operaciones mineras de estos conglomerados no se circunscriben únicamente a la fase de extracción y beneficio primario, sino que abarcan también etapas de fundición y refinación 
de metales y aleaciones, e incluso la producción de químicos como sulfato de magnesio y de sodio. Es decir, el conjunto de etapas que conforman a la industria minero-metalúrgica.

Esto no significa que existan encadenamientos con la industria metalmecánica, ni que la mayor parte de la producción minera se consuma en México. De hecho, el capital monopólico minero de base nacional continúa dependiendo de las ventas en el mercado mundial, así como de la tecnología y el financiamiento de los países desarrollados (Téllez, 2019). Pese a ello, al centrarse en la fase de extracción, la perspectiva del extractivismo deja fuera que los conglomerados mexicanos controlen no sólo varios yacimientos de clase mundial, sino también los únicos complejos metalúrgicos del país e incluso de Latinoamérica. ${ }^{1}$

En segundo lugar, el extractivismo no contempla que las operaciones de los grupos mineros mexicanos se articulan con otras actividades no extractivas en las que participan, como los servicios financieros, las telecomunicaciones, la infraestructura de transporte y la generación de energía. De no contemplar estas relaciones se corre el riesgo de no visibilizar el conjunto de elementos que han posibilitado el acrecentamiento del capital de estos grupos.

Por estos motivos, en este artículo no se utiliza el concepto de extractivismo. ${ }^{2}$ En su lugar, esta investigación se inscribe en los estudios que plantean que la acumulación de capital minero no resulta exclusivamente del "libre juego" de las fuerzas del mercado, sino de la imposición de ciertas prácticas depredatorias como la entrega masiva de títulos de concesión minera.

Desde esta perspectiva, la acumulación por desposesión en la actividad minera se trata de un conjunto de tendencias que los grupos económicos impulsan para apropiarse tanto de bienes naturales y de propiedad social (agua, bosques, suelos, fuentes de energía, además de los minerales), como de bienes públicos (reservas mineras y compañías de participación estatal), lo que les permite "obtener altas rentas a partir de ganancias extraordinarias generadas cuando esos bienes son incorporados y valorizados como mercancías en los mercados de productos o en el sistema financiero" (Rodríguez, 2017, p. 51).

De esta manera, el artículo pretende explicar las relaciones y los mecanismos de despojo que han configurado la actual lógica de funcionamiento de

1 Por ejemplo, Industrias Peñoles es dueña del complejo metalúrgico Met-Mex, el mayor productor de plata y oro afinados de América Latina y el tercero de mayor capacidad a nivel mundial (Téllez, 2019).

2 Esto no quiere decir que sus aportes deban ser ignorados, ya que varios de ellos son pertinentes y útiles al estudio del despojo en la minería. 
las grandes corporaciones mineras mexicanas, así como los impactos en su reproducción ampliada de capital.

\section{LA IMPOSICIÓN DEL MODELO NEOLIBERAL Y LA CONCENTRACIÓN DE CAPITAL MINERO}

Si bien desde 1984, durante el gobierno del expresidente Miguel De la Madrid (1982-1988), se promovió la iniciativa de Ley Reglamentaria del artículo 27 constitucional en materia de minería y en 1986 se registró la drástica liquidación de Fundidora Monterrey, la medida real que estableció las bases para la consolidación del modelo neoliberal minero fue la ejecución del Programa Nacional de Modernización de la Minería y la Ley Minera de 1992. Este programa -promovido por el Banco Mundial y operado por el gobierno del entonces presidente Carlos Salinas de Gortari-, impulsó la reforma de los marcos legales relativos a la actividad minera, básicamente los relacionados con la propiedad de la tierra, el otorgamiento de concesiones mineras y el aprovechamiento de los recursos mineros, así como los aspectos referentes a la movilidad del capital con el objetivo de crear un escenario propicio para la atracción de inversión privada (Azamar, 2018).

De esta manera fue que el gran capital minero aceptó sin reparo el cambio, ya que obtuvo diversas ventajas desde el inicio de las políticas neoliberales. Entre ellas, destaca el fomento a las exportaciones mediante el nuevo régimen de apoyo económico a las Empresas Altamente Exportadoras (ALTEX), implementado entre 1983 y 1986, y en especial el rescate crediticio por parte del Estado mexicano mediante el Fideicomiso para la Cobertura de Riesgos Cambiarios (FICORCA) (Basave, 2016). Desde 1983 y hasta 1992, este fideicomiso, diseñado y operado por Ernesto Zedillo, ofreció el prepago y la reconversión de la deuda externa adquirida por las compañías mexicanas -entre ellas las mineras-, durante las décadas de los sesenta y setenta. En especial, la medida sirvió para rescatar de la crisis de su deuda externa privada a los grandes grupos económicos de base nacional, que concentraron $80 \%$ de los recursos del fideicomiso, algo así como US $\$ 10$ mil millones de los cerca de US\$12 mil millones originalmente considerados (Fernández, 2009). El resultado del salvamento crediticio fue que estas compañías lograron recuperar su capacidad financiera, posibilitando así la obtención de los recursos económicos para adquirir los activos estatales que ulteriormente serían privatizados.

La desincorporación de las reservas mineras nacionales fue la primera acción con la que dio comienzo la modernización propiamente de este sector, 
esta medida consistió en la declaración como terreno libre ${ }^{3}$ de poco más del 98\% de las zonas de reserva minera que el Estado había creado con el objetivo de satisfacer demandas futuras del país o preservar minerales estratégicos. Se trató de un proceso apresurado, ya que de un total de 6453700 de hectáreas de reserva minera registradas hasta 1989, se pasó a sólo 146300 hectáreas en 1996 (Sánchez y Casado, 2018). Este desistimiento del Estado sobre estas zonas de reserva fue aprovechado sin lugar a dudas por los grupos mineros mexicanos.

La segunda medida que ejecutó el gobierno mexicano fue la privatización de las compañías minero-metalúrgicas con participación estatal. Se trató pues de un proceso acelerado, ya que en sólo seis años se vendieron 23 de las principales empresas mineras con participación estatal, mayoritaria y minoritaria, beneficiando de nuevo a los grandes grupos mineros de base nacional (véase tabla 1$)$.

Entre las primeras y más destacadas ventas se encuentra el remate en 1989 de la participación estatal de la Compañía Minera de Cananea, uno de los mayores yacimientos de cobre en explotación en el mundo. Después de que canceló dos licitaciones en las que participaron Protexa Monterrey e Industrias Peńoles ofreciendo US\$975 y 650 millones, respectivamente, el Estado mexicano adjudicó la histórica compañía a Grupo México por sólo US\$175 millones, valor 3.7 veces inferior a lo propuesto por Protexa Monterrey (Gómez, 2014).

Grupo México, encabezado entonces por Jorge Larrea, obtuvo además la cancelación del contrato colectivo, cuyo valor se calculaba en 1989 en MXN\$10 mil millones, a cambio de otorgar el 5\% de las acciones de la compañía a los trabajadores que se mantuvieran en escena tras la privatización. Unos meses después, tras revocar el contrato colectivo de los mineros y con el saneamiento financiero por parte del Estado, Grupo México adquirió la mina La Caridad por aproximadamente US $\$ 680$ millones (una tercera parte de su valor) (Barranco, 2014).

Fue ese mismo año cuando el grupo para México, de Alonso Ancira Elizondo y Xavier Autrey Maza, subsidiaria de Grupo Acerero del Norte, compró la compañía Real del Monte y Pachuca -importante productora de plata y oro- por US\$6 millones, a pesar de que su valor se estimaba en US\$105 millones. A raíz de esta privatización 2500 mineros fueron despedidos, lo que

3 Por terreno libre se entiende aquella parte del subsuelo "que no tenga actividad minera vigente o esté reservada para actividades de transmisión de energía o hidrocarburos" (Transparencia Mexicana, 2020, p. 41). 


\section{Tabla 1. Relación de las principales compañías mineras privatizadas a favor de grupos mineros de base nacional, 1988-1993}

\begin{tabular}{|c|c|c|c|c|c|}
\hline $\begin{array}{l}\text { Nombre de } \\
\text { la compañía }\end{array}$ & $\begin{array}{c}\text { Año de inicio } \\
\text { de participación } \\
\text { estatal }\end{array}$ & $\begin{array}{l}\text { Participación } \\
\text { estatal (\%) }\end{array}$ & $\begin{array}{c}\text { Año de } \\
\text { privatización }\end{array}$ & $\begin{array}{l}\text { Grupo minero } \\
\text { adquiriente }\end{array}$ & $\begin{array}{c}\text { Grupo } \\
\text { económico }\end{array}$ \\
\hline $\begin{array}{l}\text { Impulsora Minera de } \\
\text { Angangueo (IMASA) }\end{array}$ & 1955 & 36 & 1988 & Industrial Minera México & Grupo México \\
\hline Refractarios Mexicanos & 1974 & 33 & 1988 & Industrias Peñoles & Grupo Bal \\
\hline Cía. Minera Cedros & 1970 & 15 & 1989 & Industrias Peñoles & Grupo Bal \\
\hline Cía. Minera Cananea & 1971 & 91 & 1989 & Industrial Minera México & Grupo México \\
\hline La Caridad & 1970 & 44 & 1989 & Industrial Minera México & Grupo México \\
\hline Minera Lampazos & 1970 & 32 & 1989 & Minera Frisco & Grupo Carso \\
\hline Minera Real de Ángeles & 1969 & 32 & 1989 & Minera Frisco & Grupo Carso \\
\hline Refractarios Hidalgo & 1981 & n.d. & 1989 & Industrias Peñoles & Grupo Bal \\
\hline Química Fluor & n.d. & 17 & 1989 & Minera Frisco & Grupo Carso \\
\hline $\begin{array}{l}\text { Cía. Real del Monte y } \\
\text { Pachuca }\end{array}$ & 1948 & 100 & 1990 & PARA México & Grupo Acerero del Norte \\
\hline Carbón y Minerales Coahuila & n.d. & 100 & 1991 & Altos Hornos de México & Grupo Acerero del Norte \\
\hline Cerro de Mercado (CEMESA) & n.d. & 100 & 1991 & Altos Hornos de México & Grupo Acerero del Norte \\
\hline Cía. Carbonífera La Sauceda & n.d. & 100 & 1991 & Altos Hornos de México & Grupo Acerero del Norte \\
\hline Cía. Minera El Mamey & n.d. & 100 & 1991 & Altos Hornos de México & Grupo Acerero del Norte \\
\hline $\begin{array}{l}\text { Cía. Minera La Florida de } \\
\text { Múzquiz }\end{array}$ & n.d. & 100 & 1991 & Altos Hornos de México & Grupo Acerero del Norte \\
\hline $\begin{array}{l}\text { Complejo Minero Benito } \\
\text { Juárez Peña Colorada }\end{array}$ & 1967 & 100 & 1991 & Altos Hornos de México & Grupo Acerero del Norte \\
\hline La Perla & n.d. & 100 & 1991 & Altos Hornos de México & Grupo Acerero del Norte \\
\hline Minas de California & 1974 & 100 & 1991 & Industrias Peñoles & Grupo Bal \\
\hline Minera del Norte (MINOSA) & n.d. & 100 & 1991 & Altos Hornos de México & Grupo Acerero del Norte \\
\hline $\begin{array}{l}\text { Minerales Monclova } \\
\text { (MIMOSA) }\end{array}$ & n.d. & 100 & 1991 & Altos Hornos de México & Grupo Acerero del Norte \\
\hline Refractarios H.W. Flir & 1974 & n.d. & 1991 & Industrias Peñoles & Grupo Bal \\
\hline $\begin{array}{l}\text { Minera Carbonífera Río } \\
\text { Escondido (MICARE) }\end{array}$ & 1977 & 100 & 1992 & Altos Hornos de México & Grupo Acerero del Norte \\
\hline Cía. Minera Autlán & 1974 & 35 & 1993 & Grupo Ferrominero & Autlán Holding \\
\hline
\end{tabular}

Nota: n.d.: no disponible.

Fuente: elaboración propia con base en Concheiro (1996), Morales (2002), Sariego et al. (1988) y Urías (1980). 
propició la desaparición de la Sección Uno del Sindicato Nacional de Trabajadores Mineros, Metalúrgicos y Similares de la República Mexicana (Ortega, 1996). La ola de privatizaciones conllevó no sólo al remate de los complejos mineros estatales, sino también al despido masivo de trabajadores, la mutilación de los contratos colectivos y la disolución de sindicatos, prácticas repetidas sistemáticamente durante los siguientes años (Morales y Téllez, 2016).

Una vez realizada la privatización de los complejos minero-metalúrgicos, así como de las reservas federales, resultando claramente beneficiados los grupos económicos controlados por el capital monopólico nacional, el Estado mexicano realizó una serie de reformas constitucionales importantes, algunas concernientes directamente a la minería y otras relacionadas estrechamente con esta actividad económica, con el objetivo explícito de atraer la inversión extranjera directa. Entre dichas reformas destacan:

- Modificación del artículo 27 constitucional en noviembre de 1991 y de su Ley reglamentaria en materia ejidal en febrero de 1992. Esta reforma facilitó la adquisición de territorios ejidales y de propiedad colectiva.

- Reforma de Ley minera en 1992. Entre otros rasgos, esta ley declaró a la minería como una actividad preferente sobre cualquier otro uso o aprovechamiento del terreno donde se encuentran los minerales, al mismo tiempo que amplió la duración de las concesiones de 25 a 50 años con la posibilidad de prorrogarse por otros 50, sin límite para la extensión de la superficie concesionada y asignando un monto ínfimo por el pago de derechos.

- Reforma a la Ley de Aguas Nacionales de 1992. Esta reforma permitió el acaparamiento privado de este recurso vital, aun en sitios con estrés hídrico.

- Modificación de la Ley de Inversión Extranjera en 1993. A través de esta reforma se abrió la puerta a la creación de sociedades empresariales totalmente extranjeras que pueden repatriar la totalidad de sus utilidades sin mayores condiciones.

- Firma del Tratado de Libre Comercio con América del Norte (TLCAN). Este acuerdo comercial sentó las bases para debilitar a los empresarios nacionales que no tuvieran las condiciones económicas de competencia, profundizando la monopolización sectorial.

- Reforma del artículo 28 constitucional en 1998. Este cambio implicó la privatización del sistema ferroviario nacional, un proceso a través del cual se beneficiaron varias compañías mineras nacionales.

- Legislación ambiental laxa. Además de las reformas mencionadas, se estableció un marco regulatorio favorable mediante el cual las empresas mineras pudieron operar sin una verificación ambiental eficaz. 
Merced al conjunto de estas reformas y medidas económicas de corte neoliberal, la minería mexicana transitó de una estructura mixta dominada por empresas estatales y privadas nacionales, a una industria controlada por los grupos mineros mexicanos y una presencia cada vez mayor de corporaciones de capital extranjero, en especial de compañías canadienses orientadas a la explotación de metales preciosos. Aunque efectivamente se eliminaron las restricciones para que la inversión foránea pudiera de nueva cuenta participar de manera mayoritaria, los claros beneficiarios de la acumulación basada en la privatización de activos estatales fueron: Grupo México, Grupo Peñoles, Grupo Acerero del Norte, Minera Frisco y Grupo Ferrominero (hoy Autlán Holding), mismos que aprovecharon la benevolencia del Estado no sólo para consolidar su control sobre los principales yacimientos y plantas metalúrgicas del país, sino también para lograr una mayor integración vertical y/o diversificarse hacia otras ramas económicas, dirigir nuevas inversiones fuera del país (Basave, 2016) e incluso absorber importantes operaciones extranjeras como el caso de Grupo México que, en "una ironía de la historia" (Delgado Wise y Del Pozo, 2001, p. 124), el 17 de noviembre de 1999 compró los activos minero-metalúrgicos de ASARCo en Estados Unidos.

\section{LA EXPANSIÓN TERRITORIAL EN MÉXICO DEL GRAN CAPITAL MINERO A PRINCIPIOS DEL SIGLO XXI}

La privatización de casi todas las empresas con inversión pública (mayoritaria y minoritaria) significó una transferencia radical de activos a favor del mismo grupo de "hijos predilectos del Régimen" formados durante el periodo de mexicanización (Delgado Wise y Del Pozo, 2001, p. 113). Sin embargo, a partir del siglo xxI dichos capitales reforzaron nuevamente su concentración gracias al acaparamiento de enormes áreas del subsuelo nacional, impulsado por el ciclo alcista de las cotizaciones internacionales de los metales preciosos (2001-2012), el segundo más largo desde la década de los setenta del siglo xx cuando el entonces presidente estadounidense Richard Nixon declaró la inconvertibilidad del dólar en oro (Farhi, 1999; Verbruggea y Geenen, 2019).

Desde 1992, cuando se modificó la Ley Minera, la superficie concesionada comenzó a crecer, en especial durante la administración del presidente Ernesto Zedillo cuando las hectáreas en concesión ascendieron a 992783 (véase figura 1), y es hasta la primera década del siglo Xxi cuando se registró el aumento inédito de la superficie concesionada, tendencia que mantuvo una relación de causalidad entre el alza en los índices de los precios de los metales 
preciosos y de los derivados de oro. Dicha correspondencia fue mucho más pronunciada entre 2007 y 2012, cuando se entregaron concesiones mineras por 3587 hectáreas en promedio, lo que coincidió con el periodo de altos precios internacionales de los metales preciosos. Aunque durante la administración del presidente Enrique Peña (2013-2018) se aprecia una caída, la superficie acumulada hasta diciembre de 2017 fue de aproximadamente 35891 hectáreas concesionadas, de las cuales 21 millones se encuentran en calidad de vigentes, cubriendo $11 \%$ del territorio nacional (Secretaría de Economía, 2018) (véase figura 1).

La concentración de títulos de concesión minera por parte de los cinco principales grupos mineros mexicanos ocupa un sitio relevante. Hasta diciembre de 2017 estas compañías controlaban 24\% de la superficie otorgada en concesión en México mediante poco más de cuatro mil títulos mineros (para exploración, explotación y beneficio de minerales metálicos y no metálicos).

Figura 1. Índice de precios de metales preciosos y superficie otorgada en concesión en México, 2000-2018 $(2016=100)^{*}$

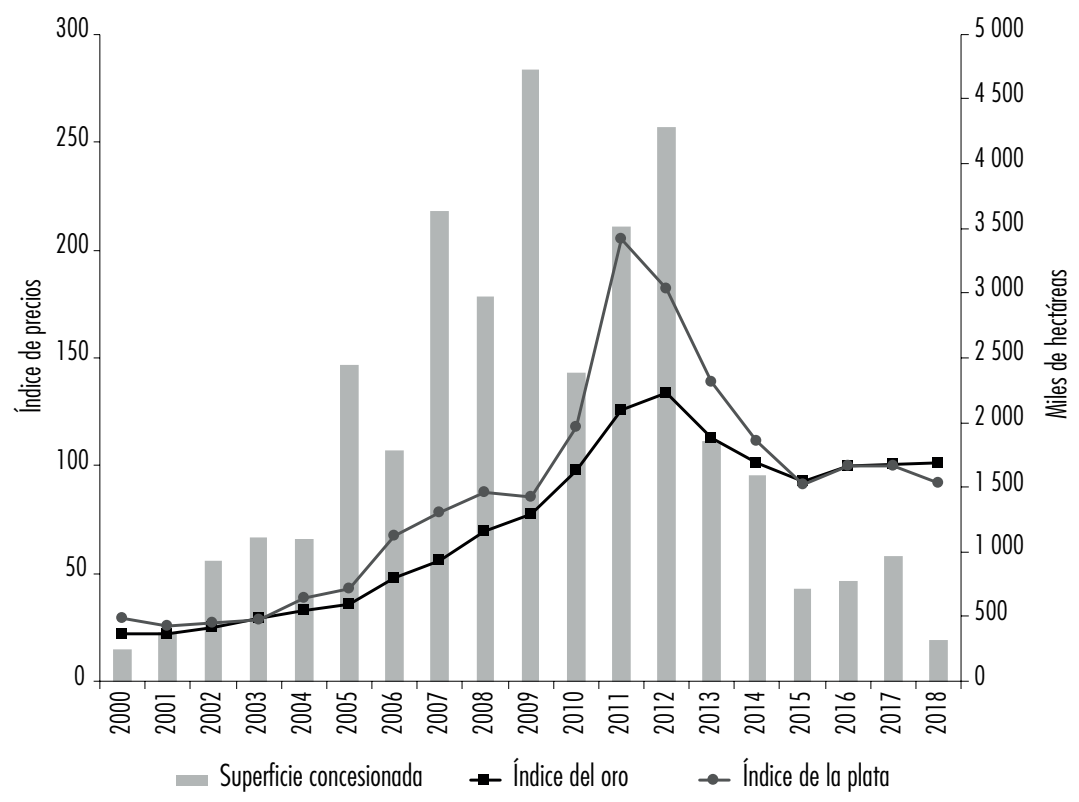

Nota: * la superficie concesionada incluye tanto el otorgamiento de los nuevos lotes mineros como aquellos que implicaron reducciones y ampliaciones.

Fuente: elaboración propia con información de la Secretaría de Economía (2018), SGM (2020) y Presidencia de la República (2019). 
Isidro Téllez Ramírez y Aleida Azamar Alonso

Tabla 2. Concesiones por grupo minero mexicano, 2017*

\begin{tabular}{lcccc}
\hline Grupo minero & $\begin{array}{c}\text { Superficie (miles } \\
\text { de hectáreas) }\end{array}$ & $\begin{array}{c}\text { Participación respecto de } \\
\text { la superficie concesionada } \\
\text { nacional (\%) }\end{array}$ & $\begin{array}{c}\text { Número } \\
\text { de títulos }\end{array}$ & $\begin{array}{c}\text { Participación } \\
\text { respecto del total } \\
\text { nacional (\%) }\end{array}$ \\
\hline Altos Hornos de México & 3576 & 10.0 & 394 & 1.2 \\
Grupo Peñoles & 3306 & 9.2 & 2280 & 6.8 \\
Minera Frisco & 1060 & 3.0 & 833 & 2.5 \\
Grupo México & 693 & 1.9 & 834 & 2.5 \\
Autlán & 19 & 0.1 & 60 & 0.2 \\
Subtotal & 8653 & 24.1 & 4401 & 13.2 \\
Resto de empresas & 27238 & 75.9 & 28902 & 86.8 \\
Total & 35891 & 100.0 & 33303 & 100.0 \\
\hline
\end{tabular}

Nota: *la superficie concesionada incluye tanto el otorgamiento de los nuevos lotes mineros como aquellos que implicaron reducciones y ampliaciones.

Fuente: elaboración propia con información de la Secretaría de Economía (2018).

Altos Hornos de México y Grupo Peñoles destacan como las mayores companías concesionarias mexicanas, ya que en conjunto acapararon prácticamente dos de cada diez hectáreas otorgadas en concesión (véase tabla 2).

De las 35.8 millones de hectáreas concesionadas en total en México, Altos Hornos de México posee el mayor número con 3576 hectáreas, las cuales se concentran entre los estados de Coahuila y Nuevo León, y en menor medida en Oaxaca, Sonora, Hidalgo y Michoacán. El segundo lugar lo ocupa Grupo Peñoles (incluida su subsidiaria, Fresnillo Plc), al controlar 3306 hectáreas concesionadas que se distribuyen en 22 de las 32 entidades federativas del país, concentrándose en Zacatecas, Sonora, Durango y Chihuahua (véase figura 2).

Si bien los minerales en el subsuelo siguen siendo propiedad de la nación (DOF, 2012), el acaparamiento de tal superficie concesionada por parte de estos "neolatifundistas mineros", es un elemento asociado a una ventaja monopólica crucial que supone cierto tipo de barrera geográfica a la entrada de otras compañías que no la poseen. Lo que significa que el acaparamiento de lotes mineros permite un aprovechamiento privado de los bienes del Estado, que deriva en la apropiación de ganancias extraordinarias que surgen precisamente del derecho exclusivo de propiedad que los grupos mineros mexicanos detentan sobre grandes proporciones del subsuelo, que pueden tener cualidades geológicas y económicas de excepción y que aprovechan en el momento que 


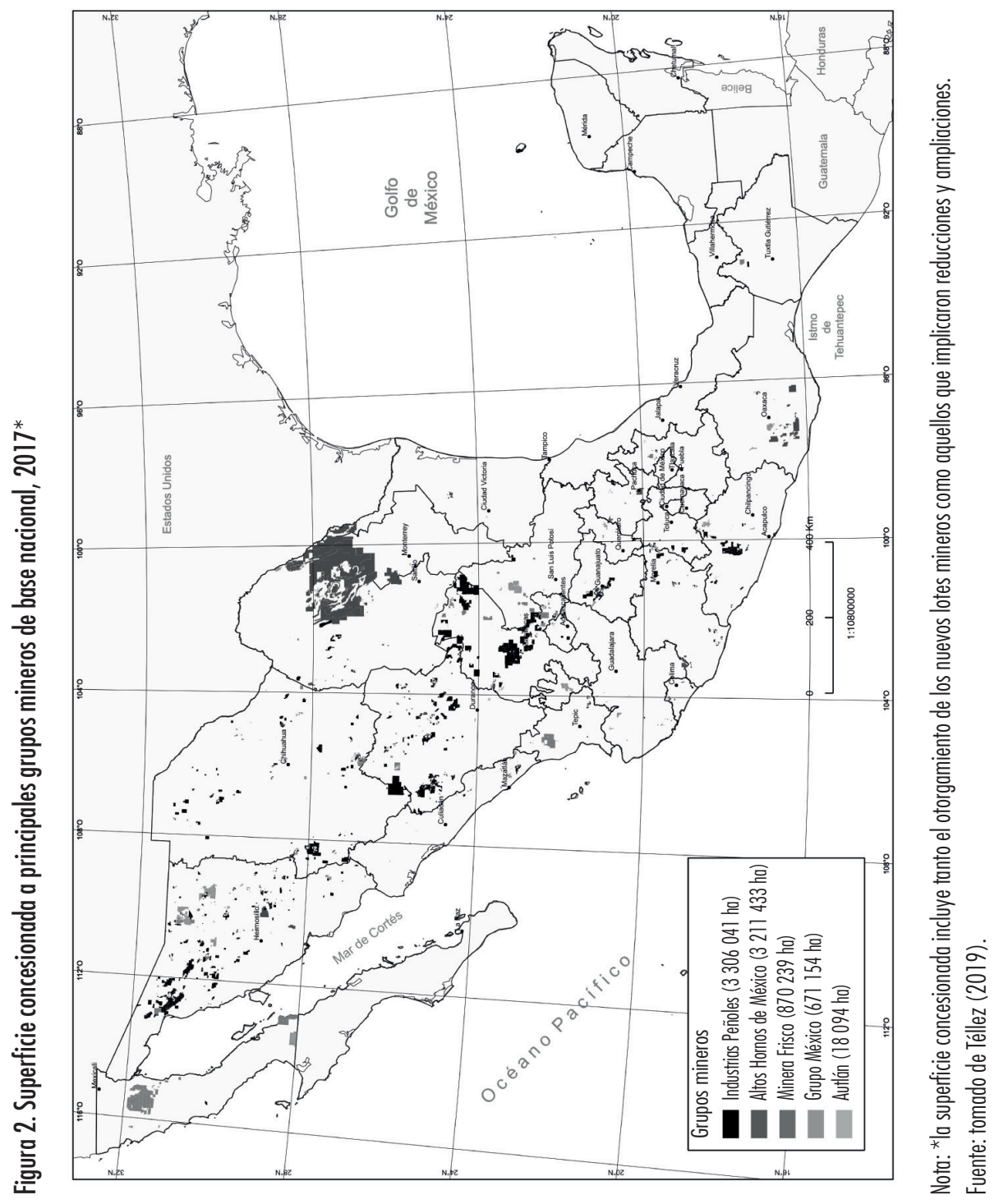


a ellos mejor les convenga (Delgado Wise y Del Pozo, 2001). Es decir, dichas empresas se apropian de una renta que comienza con la acumulación basada en la concesión de los minerales que el Estado posee en nombre del pueblo que representa, pero que sólo deviene en ganancia extraordinaria porque los recursos mineros se pueden apropiar precisamente de manera excluyente. Por lo que la acumulación basada en el aumento del número de títulos y hectáreas controlados es resultado del grado de concentración alcanzado por el gran capital durante las últimas décadas, además de que es su condición material (Téllez, 2020).

De manera que la distribución geográfica de las 50 unidades mineras que hasta 2018 controlaban los cinco grupos mineros, 29 de ellas en manos de Grupo México e Industrias Peñoles, coincide con las entidades federativas donde han adquirido concesiones mineras (véase tabla 3). Dicha sintonía territorial exhibe el control sobre los actuales yacimientos en explotación, así como sobre posibles descubrimientos, en especial en las provincias metalogenéticas Sierra Madre Occidental, Sierra Madre Oriental y Mesa Central, áreas

Tabla 3. Principales minas de los grupos mineros mexicanos, 2018

\begin{tabular}{|c|c|c|c|c|}
\hline Grupo minero & Holding & $\begin{array}{l}\text { Número } \\
\text { de minas }\end{array}$ & $\begin{array}{l}\text { Principales } \\
\text { operaciones }\end{array}$ & $\begin{array}{l}\text { Entidades } \\
\text { federativas }\end{array}$ \\
\hline Industrial Minera México & Grupo México & 12 & $\begin{array}{l}\text { San Martín, La Caridad, } \\
\text { Buenavista, Taxco, Charcas, } \\
\text { Nueva Rosita, Santa Bárbara, } \\
\text { Santa Eulalia }\end{array}$ & $\begin{array}{l}\text { Sonora, Chihuahua, } \\
\text { Coahuila, Zacatecas, } \\
\text { San Luis Potosí, Guerrero }\end{array}$ \\
\hline Industrias Peñoles & Grupo Bal & 17 & $\begin{array}{l}\text { Milpillas, Tizapa, Capela, } \\
\text { Velardeña, Laguna del Rey, } \\
\text { Bismark, Sabinas, Madero, } \\
\text { Fresnillo, Saucito, La Herradura, } \\
\text { San Julián, Ciénega }\end{array}$ & $\begin{array}{l}\text { Sonora, Chihuahua, } \\
\text { Coahuila, Durango, } \\
\text { Zacatecas, San Luis } \\
\text { Potosí, México, Guerrero }\end{array}$ \\
\hline Altos Hornos de México & $\begin{array}{l}\text { Grupo Acerero del } \\
\text { Norte }\end{array}$ & 9 & $\begin{array}{l}\text { Real del Monte, Baztán, } \\
\text { Hércules, CEMESA, La Perla, } \\
\text { MIMOSA, MICARE }\end{array}$ & $\begin{array}{l}\text { Coahuila, Chihuahua, } \\
\text { Durango, Hidalgo, } \\
\text { Michoacán }\end{array}$ \\
\hline Minera Frisco & Grupo Carso & 8 & $\begin{array}{l}\text { El Coronel, Tayahua, María, } \\
\text { Ocampo, San Felipe, Concheño, } \\
\text { Asientos, El Porvenir }\end{array}$ & $\begin{array}{l}\text { Baja California, Sonora, } \\
\text { Chihuahua, Zacatecas, } \\
\text { Aguascalientes }\end{array}$ \\
\hline Compañía Minera Autlán & $\begin{array}{l}\text { Autlán Holding (Grupo } \\
\text { Ferrominero) }\end{array}$ & 4 & $\begin{array}{l}\text { Molango, Nonoalco, Naopa, } \\
\text { Columbia }\end{array}$ & Hidalgo \\
\hline Total & & 50 & & \\
\hline
\end{tabular}

Fuente: elaboración propia con base en Sánchez et al. (2014) y Sánchez y Casado (2018). 
donde se encuentran los depósitos cupríferos, auroargentíferos, ferríferos y carboníferos más importantes del país (Sánchez y Casado, 2018).

El mayor ejemplo es AHMSA, ya que cuatro de las nueve instalaciones mineras que posee se ubican en Coahuila, entidad donde el grupo obtuvo más de 2.5 millones de hectáreas en concesión cuya vigencia concluye en promedio hasta el 2050 (como se puede observar en la figura 2).

\section{5. ¿QUIÉN CONTROLA LA MINERÍA MEXICANA EN EL SIGLO XXI?}

Al mismo tiempo del proceso de concentración de concesiones mineras que marca una abierta política del despojo (Azamar, 2017), los grupos mineros mexicanos fortalecen su capacidad de control sobre la producción nacional durante el periodo de bonanza, además de que refuerzan la diversificación e internacionalización de sus actividades. El incremento de las cotizaciones internacionales de los principales metales que México produce y exporta, fue un factor clave para que el gran capital minero de base nacional aumentara su dominio sobre la minería mexicana, al grado de que en 2018 concentró 31\% de la producción nacional de oro y $41 \%$ de plata, sobresaliendo Fresnillo Plc como el mayor productor nacional de metales preciosos con una participación de $24 \%$ para el caso del oro y de $29 \%$ para la plata, porcentajes por arriba de los obtenidos por Torex Gold, Agnico Eagle y Newmont Goldcorp, sus principales competidores. Respecto al cobre, los grupos mineros mexicanos controlaron $85 \%$ de la producción de este metal en el mismo ańo, figurando Grupo México como el principal productor cuprífero del país con una participación de $74 \%$. En tanto que, para el zinc y el plomo, las empresas mexicanas participaron con 81 y $87 \%$ de la producción total, respectivamente (CAMIMEX, 2019) (véase tabla 4).

Es en la producción nacional de minerales preciosos donde el capital extranjero aumenta su participación, en especial, en la extracción de oro. Newmont Goldcorp, Torex Gold, Agnico Eagle y Alamos Gold son algunas de las principales empresas foráneas que incrementaron su producción aurífera en México durante los últimos años. Incluso se puede decir que el ingreso de estas corporaciones (prácticamente de todas es de capital canadiense), ha sido el factor de la "aurificación" de la minería mexicana (Casado y Sánchez, 2019), pues este metal pasó de una participación de 3.8\% durante los años ochenta del siglo Xx, a representar $21 \%$ del valor de la producción nacional en el 2000 y $16 \%$ en 2018 (véase figura 3). 
Figura 3. Evolución de la participación porcentual de los principales productos en el valor de la producción minera nacional, 1980-2000-2018

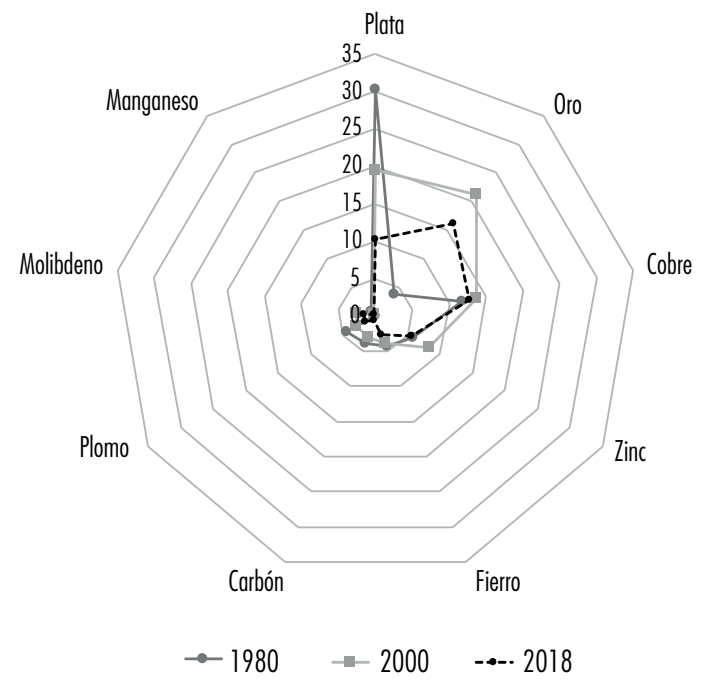

Fuente: elaboración propia con datos de Sánchez et al. (2014) y SGM (2019).

Sin embargo, la participación del capital foráneo se diluye en el negocio de la fundición y refinación, áreas en las que el control por parte de los dos principales grupos mineros mexicanos es total. De manera similar al oligopolio de los años cincuenta del siglo Xx, en la refinación de metales preciosos, que estuvo dominado por American Smelting and Refining (ASARCO), American Metal Climax (amax) y Anaconda Copper que tanto daño provocó a la competencia y al desarrollo industrial local en el país; en la actualidad se ha formado otro núcleo empresarial integrado por Grupo México e Industrias Peñoles, únicas compañías que participan en la fundición y refinación de oro primario en México, provocando de nuevo límites a la competencia y el desarrollo de cadenas productivas independientes.

En 2018, ambos grupos totalizaron un volumen de 1.3 millones de onzas de oro primario afinado, 88\% de Industrias Peñoles y 12\% de Grupo México (véase tabla 4). Producción metalúrgica que se abastece de concentrados y barras doré de las minas de los grupos mexicanos, así como de yacimientos de compañías foráneas, entre las que resalta Newmont Goldcorp (CAMIMEX, 2019).

4 Barras hechas de una aleación de oro y plata. 
Tabla 4. Participación de las principales empresas en la producción minera nacional, 2018

\begin{tabular}{|c|c|c|c|c|c|c|c|c|c|}
\hline \multicolumn{2}{|c|}{ Oro } & \multicolumn{2}{|l|}{ Plata } & \multicolumn{2}{|c|}{ Cobre } & \multicolumn{2}{|c|}{ Zinc } & \multicolumn{2}{|c|}{ Plomo } \\
\hline Compañía & $\%$ & Compañía & $\%$ & Compañía & $\%$ & Compañía & $\%$ & Compañía & $\%$ \\
\hline Fresnillo Plc & 24 & Fresnillo Plc & 29 & $\begin{array}{l}\text { Grupo } \\
\text { México }\end{array}$ & 74 & Peñoles & 29 & $\begin{array}{l}\text { Fresnillo } \\
\text { Plc }\end{array}$ & 22 \\
\hline Torex Gold & 9 & $\begin{array}{l}\text { Newmont } \\
\text { Goldcorp }\end{array}$ & 9 & Peñoles & 4 & $\begin{array}{l}\text { Newmont } \\
\text { Goldcorp }\end{array}$ & 21 & $\begin{array}{l}\text { Newmont } \\
\text { Goldcorp }\end{array}$ & 22 \\
\hline $\begin{array}{l}\text { Agnico } \\
\text { Eagle }\end{array}$ & 9 & Grupo México & 6 & $\begin{array}{l}\text { Grupo } \\
\text { Invecture }\end{array}$ & 4 & $\begin{array}{l}\text { Fresnillo } \\
\text { Plc }\end{array}$ & 13 & Peñoles & 12 \\
\hline $\begin{array}{l}\text { Newmont } \\
\text { Goldcorp }\end{array}$ & 7 & $\begin{array}{l}\text { Pan American } \\
\text { Silver }\end{array}$ & 6 & NEMISA & 3 & $\begin{array}{l}\text { Grupo } \\
\text { México }\end{array}$ & 10 & $\begin{array}{l}\text { Grupo } \\
\text { México }\end{array}$ & 9 \\
\hline $\begin{array}{l}\text { Minera } \\
\text { Frisco }\end{array}$ & 7 & Peñoles & 6 & $\begin{array}{l}\text { Minera } \\
\text { Frisco }\end{array}$ & 3 & $\begin{array}{l}\text { Minera } \\
\text { Frisco }\end{array}$ & 8 & $\begin{array}{l}\text { Minera } \\
\text { Frisco }\end{array}$ & 7 \\
\hline Otras & 37 & Otras & 44 & Otras & 11 & Otras & 19 & Otras & 27 \\
\hline Gran Capital & $\%$ & & $\%$ & & $\%$ & & $\%$ & & $\%$ \\
\hline Nacional & 31 & Nacional & 41 & Nacional & 85 & Nacional & 60 & Nacional & 40 \\
\hline Extranjero & 32 & Extranjero & 15 & Extranjero & 4 & Extranjero & 21 & Extranjero & 22 \\
\hline Total & 63 & Total & 56 & Total & 89 & Total & 81 & Total & 62 \\
\hline
\end{tabular}

Fuente: tomado de Sánchez et al. (2019).

Este nivel de concentración de la producción metalúrgica se repite respecto a la afinación y refinación de la plata, cobre, plomo y zinc, pues estos conglomerados controlan las únicas plantas de refinación primaria de estos metales que existen en México: Met Mex en Torreón, de Industrias Peñoles, y la refinería de San Luis Potosí de Grupo México (camimex, 2013). Grupo México es la única compañía que logra integrar verticalmente extracción, beneficio y refinación de los yacimientos cupríferos del país. Industrias Peńoles, por su parte, ostenta la hegemonía nacional en la refinación primaria del resto de los principales metales que se producen en México: 89\% de la plata afinada, 69\% del zinc afinado y, 100\% del plomo afinado. Este control es lo que posiciona al grupo como el principal productor mundial de plata afinada y lo ubica entre los principales productores globales de zinc ( $2.5 \%$ de la producción mundial) y plomo afinados (3\% del total mundial) (CAMimex, 2019) (véase tabla 5).

No obstante, si se compara el valor de las ventas y de los activos totales registrados durante los primeros 15 años del siglo xxi, Grupo México es el 
Tabla 5. Participación porcentual de Industrias Peñoles y Grupo México en la producción metalúrgica nacional, 2018*

\begin{tabular}{lcccc}
\hline Grupo minero & Oro & Plata & Plomo & Zinc \\
\hline Industrias Peñoles & 88 & 89 & 100 & 69 \\
Grupo México & 12 & 11 & & 31 \\
Total Nacional & 100 & 100 & 100 & 100 \\
\hline
\end{tabular}

Fuente: elaboración propia con datos de CAMIMEX (2019, pp. 277-301).

principal grupo minero del país. Aunque su formación se derivó gracias a compadrazgos y asignaciones directas de importantes empresas mineras privatizadas (Azamar, 2019), su actual situación se consolidó durante los gobiernos de los presidentes Vicente Fox y Felipe Calderón. Como se aprecia en la figura 4, este grupo minero multiplicó por seis sus ventas netas al pasar de un valor de MXN\$17 mil millones en el 2000, al registrar poco más de MXN\$102 mil millones en 2010.

La tendencia favorable para Grupo México fue aún mayor en el rubro de activos totales, ya que a pesar de la crisis económica mundial de 2008, su valor se multiplicó por 11 al pasar de MXN\$17 500 millones en el 2000, lo que significa poco más de MXN\$195 mil millones en 2010, descendiendo a MXN\$158 mil en 2015 como parte del proceso recesivo registrado por el sector minero global (véase figura 5).

Los grupos mineros mexicanos se distinguen porque durante las últimas tres décadas han reforzado la integración vertical y diversificación de sus actividades, al grado de que cada vez es más difícil distinguir la actividad principal en torno de la cual se organizan las otras (Dos Santos, 2016). Sus inversiones van desde la minería y metalurgia, pasando por los transportes y las comunicaciones, el sector inmobiliario y hotelero, la construcción de infraestructura industrial y urbana, la banca y los servicios financieros, hasta inversiones en el comercio y recientemente en el complejo petrolero nacional. Gama de inversiones que administran mediante distintas filiales, siempre bajo la dirección y el control accionario de empresas centrales o holdings: Grupo México, Grupo Bal, Grupo Acerero del Norte, Grupo Carso y Autlán Holding.

Ejemplo más claro de dicha diversificación es Grupo México al mantener negocios en la actividad minera, del transporte y de infraestructura. Además de que ocho de sus filiales mineras tienen presencia en seis países: México, Estados Unidos, Perú, Ecuador, Chile y Argentina (Grupo México, 2018). 
Figura 4. Ventas netas de Industrias Peñoles* y Grupo México, 2000-2015

(millones de pesos; 2010=100)

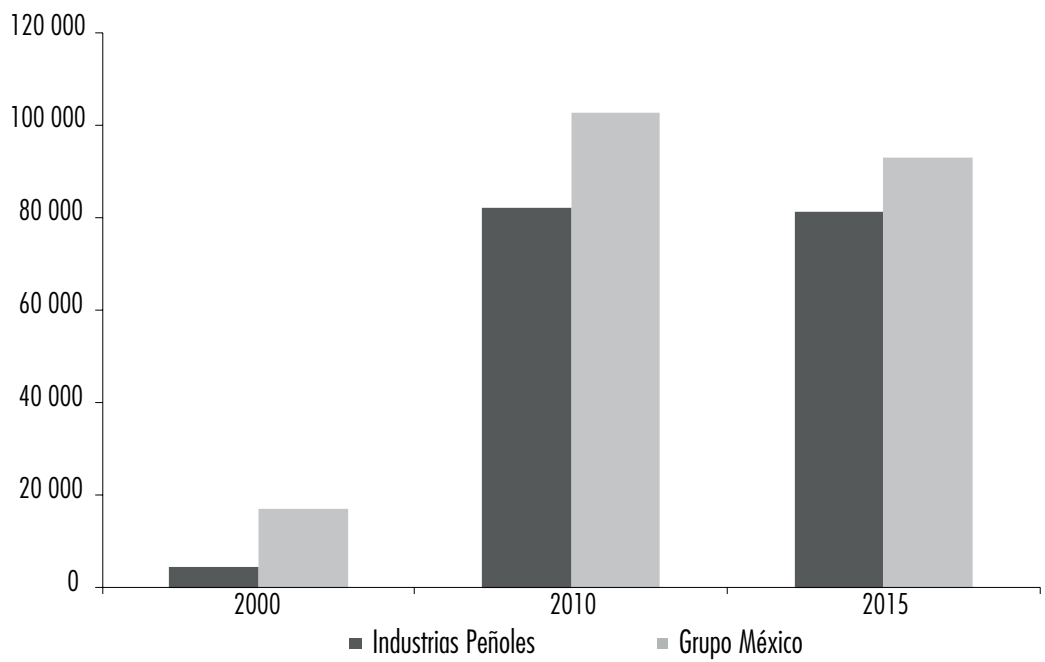

*Nota: a partir de 2010 incluye las cifras reportadas por Fresnillo Plc.

Fuente: elaboración propia con información de la Revista Expansión (2001, 2011 y 2016).

Figura 5. Activos totales de Industrias Peñoles* y Grupo México, 2000-2015

(millones de pesos; 2010=100)

200000

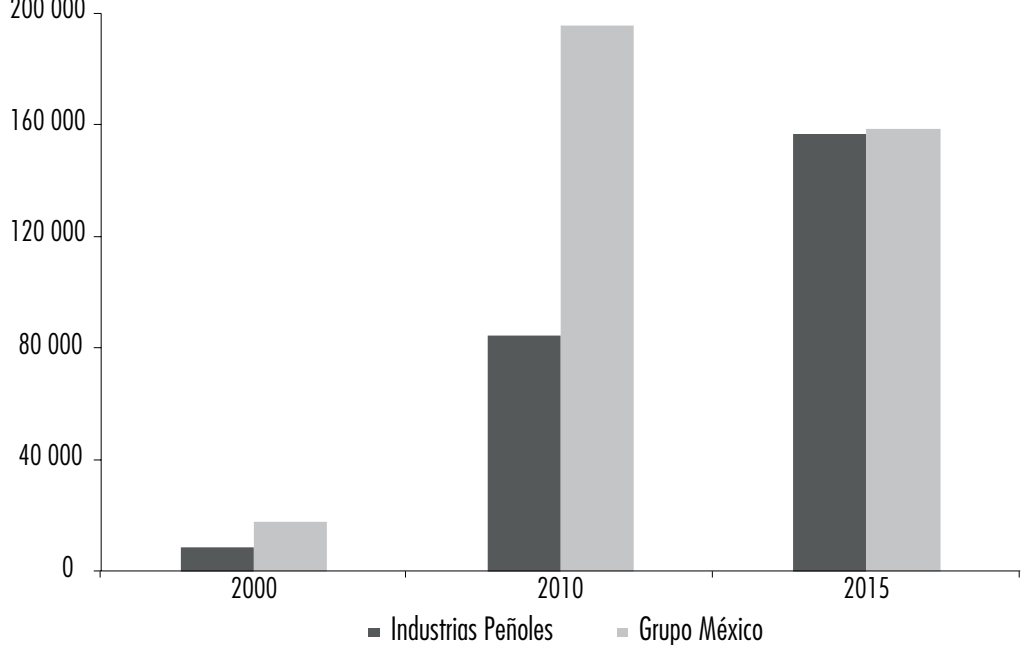

Nota: *a partir de 2010 incluye las cifras reportadas por Fresnillo Plc.

Fuente: elaboración propia con información de la Revista Expansión (2001, 2011 y 2016). 
Este grado de integración, diversificación e internacionalización alcanzado durante las últimas décadas por el gran capital minero de base nacional, inexorablemente ha ocasionado un aumento notable de ganancias. El caso más emblemático es el de Germán Larrea Mota Velasco, accionario mayoritario de Grupo México, quien durante los periodos presidenciales de Vicente Fox y Felipe Calderón multiplicó su riqueza personal por 17, al pasar de US\$mil millones en 2001 a US\$16 700 millones en 2012. Hecho que lo ha colocado por más de una década como el segundo hombre más rico de México y el número 79 del mundo, sólo por debajo de Carlos Slim (primer sitio nacional y séptimo mundial) y arriba de Alberto Baillères (tercero nacional y 143 mundial) (Fernández, 2013; Medina, 2018), este último, multiplicó por seis su riqueza, al pasar de US $\$ 2.8$ millones en 2006 a US $\$ 16.5$ millones en 2012; es decir, al año sumó US $\$ 2.2$ millones en promedio a su fortuna personal (Maldonado, 2016).

\section{REFLEXIONES FINALES}

Después de más de tres décadas de neoliberalismo, el sector minero-metalúrgico mexicano continúa bajo el control de cinco grupos mineros de base nacional: Grupo México, Industrias Peñoles, Grupo Acerero del Norte, Minera Frisco y Grupo Autlán. Además de la extracción de minerales industriales, estas corporaciones mantuvieron una posición oligopólica en la refinación de oro y plata, industria que no presentan competencia al interior del país.

Este ascenso se nutrió de una política de despojo franco de los recursos naturales y productivos nacionales basada en la desincorporación de reservas mineras federales, la privatización de operaciones altamente productivas y el acaparamiento de concesiones mineras, así como de la adopción de distintas reformas constitucionales. Estas medidas favorecieron no sólo el actual grado de integración vertical, sino también la diversificación e internacionalización de estos conglomerados.

Pese a esta serie de ventajas brindadas por el Estado mexicano desde 1982 y el posterior impulso recibido de la bonanza mundial registrada durante el periodo 2001-2012, no se observan esfuerzos significativos por parte del gran capital minero mexicano para fomentar la fabricación nacional de equipo y maquinaria para la actividad minera. Precisamente por la concentración de la producción, el acaparamiento territorial y los limitados controles legislativos al respecto, los grupos mineros no han logrado incidir en la reducción de la dependencia tecnológica que México tiene de países como Alemania o Suecia, 
lo cual se debe, en parte, a la reproducción del modelo de enclave, límite estructural del sector minero identificado desde hace varias décadas por Ceceña (2016 [1953]), Sariego et al. (1988) y Urías (1980).

De este modo, en la división internacional del trabajo, los grupos mineros mexicanos siguen ocupando el sitio de abastecedores de minerales y aleaciones de los países desarrollados, en especial de oro, plata, cobre, plomo y zinc. A tres décadas de que inició la privatización del sector, el gran capital mexicano sigue perpetuando el despojo minero colonial (Morales y Téllez, 2016), que no busca beneficiar directamente al país ni a los territorios donde se instalan las operaciones mineras, sino potenciar la capacidad de explotación y exportación de los bienes extraídos en provecho de la concentración de riqueza de un selecto grupo de corporaciones.

\section{BIBLIOGRAFÍA}

Azamar, A. (2017). Megaminería en México: explotación laboral y acumulación de ganancia. Universidad Autónoma Metropolitana. Editorial Itaca. https://bit.ly/37CPhEv

(2018). Minería en América Latina y México. Problemas y consecuencias. Universidad Autónoma Metropolitana. https://bit.ly/3617mBI

(2019, 15 de julio). ¿Quién es Grupo México y por qué ha logrado salir impune de los desastres mineros? El Universal. https://www.eluniversal. com.mx/columna/aleida-azamar/nacion/quien-es-grupo-mexico-y-porque-ha-logrado-salir-impune-de-los

Barranco, A. (2014, 24 de septiembre). Del cielo al infierno. El Siglo de Torreón. https://bit.ly/36G47L8

Basave, J. (2016). Multinacionales mexicanas. Surgimiento y evolución. Siglo XXI Editores-Instituto de Investigaciones Económicas, UnAM.

Cámara Minera de México (CAmimex) (2013). Informe Anual 2013. Cámara Minera de México. https://bit.ly/3gcDRer

(2019). Informe Anual 2019. Cámara Minera de México. https://bit. ly/2JDojEH

Casado, J. M. y Sánchez, M. T. (2019). Los mineros en el México neoliberal. Investigaciones Geográficas, (98). http://dx.doi.org/ $10.14350 /$ rig. 59787

Ceceńa, J. L. (2016 [1953]). Inversiones internacionales privadas en el siglo xx. En A. E. Ceceña y R. Ornelas (coords.). Las corporaciones y la economiamundo: el capitalismo monopolista y la economía mexicana en retrospectiva 
(pp. 13-50). Siglo XXI Editores-Instituto de Investigaciones EconómicasFacultad de Economía, unam.

Cohen, M. A. (2015). Conflictos socio-ambientales: la minería en Wirikuta y Cananea. El Cotidiano, (191). https://bit.ly/2VEEFPZ

Concheiro, E. (1996). El gran acuerdo: gobierno y empresarios en la modernización salinista. Era Ediciones-Instituto de Investigaciones Económicas, UNAM.

Cortés, I. (2018). La sal y la plata. Trabajo y cultura en la construcción regional del México neoliberal. Casa Chata.

Delgado Wise, R. y Del Pozo, R. (2001). Minería, Estado y gran capital en México. Economía e Sociedade, Campinas, (16). https://bit.ly/33M7GxE

Diario Oficial de la Federación (DOF) (2012, 12 de octubre). Reglamento de la Ley Minera. Diario Oficial de la Federación. https://bit.ly/3mJdjnJ

Dos Santos, T. (2016). Notas sobre la concentración económica y la acumulación del capital. En A. E. Ceceña y R. Ornelas (coords.). Las corporaciones y la economía-mundo: el capitalismo monopolista y la economía mexicana en retrospectiva (pp. 181-206). Siglo XXI Editores-Instituto de Investigaciones Económicas-Facultad de Economía, UnAM.

Farhi, M. (1999). Derivativos financeiros: hedge, especulação e arbitragem. Economia E Sociedade, Campinas, 8(2). https://bit.ly/3opzlgR

Fernández, C. (2009, 4 de abril). México SA. Los empresarios de siempre, beneficiarios del blindaje. Todos los mexicanos pagarán la deuda de los amigos. La Jornada. https://bit.ly/36Kn6V8

(2013, 27 de octubre). La fórmula del chantaje. La Jornada. https:// bit.ly/31DirZa

Garibay, C., Boni, A., Panico, F., Urquijo, P. y Klooster, D. (2011). Unequal partners, unequal exchange: Goldcorp, the Mexican state, and campesino dispossession at the Peñasquito goldmine. Journal of Latin American Geography, 10(2). http://dx.doi.org/10.1353/lag.2011.0046

Gómez, N. (2014). El colapso de la dignidad: la historia de una tragedia minera y la lucha en contra de la avaricia y corrupción en México. Colofón-La Jornada Ediciones.

Grupo México (2018). Informe Anual 2018. Reporte anual que se presenta de acuerdo con las disposiciones de carácter general aplicables a las Emisoras de Valores y a otros participantes del mercado por el ejercicio terminado al 31 de diciembre de 2018. Grupo México-Bolsa Mexicana de Valores. https://bit.ly/37DRCiu 
Guevara, B. (2016). La inversión extranjera directa en la minería en México: el caso del oro. Análisis Económico, XXXI (77). https://bit.ly/36Ip5Jy

Gudynas, E. (2015). Extractivismo. Ecología, economía y política de un modo de entender el desarrollo y la naturaleza. Centro de Documentación e Información Bolivia (CEDIB).

Harvey, D. (2007). El nuevo imperialismo. Ediciones AKAL.

Islas, M. (2017). Genealogía de Grupo México. Bo.LET.ín, Publicación del Laboratorio de estudios sobre empresas transnacionales, 4(65). http://let.iiec. unam.mx/node/ 1464

Maldonado, M. (2016, 4 de mayo). Larrea, el socio incómodo (II). El Financiero. https://bit.ly/33KCmiK

Marx, K. (2003). El capital. Tomo I. Siglo XXI.

Medina, A. (2018, 6 de marzo). Estos son los 16 mexicanos más ricos de la lista Forbes 2018. Forbes. https://bit.ly/3qscmCp

Morales, J. (2002). Transnacionalización del capital minero. En A. Coll-Hurtado, M. T. Sánchez y J. Morales (eds.). La minería en México (pp. 51-81). UNAM-Instituto de Geografía.

Morales, J. y Téllez, I. (2016). Minería: acumulación neocolonial por desposesión en México bajo el TLCAN. En J. Estay Reyno (coord.). La economía mundial y América Latina ante la continuidad de la crisis global (pp. 329-353). CLACSO-BUAP. http://biblioteca.clacso.edu.ar/clacso/se/20160823041702/ La_economia_mundial.pdf

Ortega, F. (1996). Los "Libros Blancos" indican que el grupo ganador, además, pagó sólo la mitad. Proceso 1052.

Paredes, P., Ángeles, G. y Flores, M. (2016). Determinants of leverage in mining companies, empirical evidence for Latin American countries. Contaduría y Administración, (61). http://dx.doi.org/10.1016/j.cya.2015.09.010

Presidencia de la República (2019). Primer Informe de Gobierno 2019. Gobierno de los Estados Unidos Mexicanos. https://bit.ly/3mJafbl

Revista Expansión (2001, julio). Las 500 empresas más importantes de México. Revista Expansión.

(2011, julio). Las 500 empresas más importantes de México. Revista Expansión.

(2016). Las 500 empresas más importantes de México. Revista Expansión.

Rodríguez, C. (2017). Despojo para la acumulación. Un análisis de los procesos de acumulación y sus modelos de despojo. Bajo el Volcán, 17(26). https://www.redalyc.org/articulo.oa?id=28655577003 
Sánchez, M. T., Gutiérrez, M. T. y Casado, J. M. (2014). Atlas de cambios territoriales de la economía en la sociedad en México, 1980-2011. UNAMInstituto de Geografía.

y Casado, J. M. (2018). Capítulo 5. Transformaciones en la estructura empresarial y productiva y en la organización territorial de la minería mexicana, 1980-2012. En M. T. Sánchez Salazar y M.T. Gutiérrez Vásquez de McGregor (coord.). Globalización, politicas neoliberales y transformaciones en la organización espacial de la economía mexicana a partir del decenio de 1980 (pp. 121-157). Instituto de Geografía-unam.

y Téllez, I. (2019, 11 de abril). La gran minería metálica en México en el periodo neoliberal: cambios en la estructura empresarial y productiva, expansión territorial e impacto socioeconómico regional. Ponencia presentada en el XVII Encuentro de Geógrafos de América Latina, Quito, Ecuador.

Sariego, J. L., Reygada, L., Gómez, M. Á. y Farrera, J. (1988). El Estado y la minería mexicana. Politica, trabajo y sociedad durante el siglo XX. Fondo de Cultura Económica-Secretaría de Energía, Minas e Industria Paraestatal.

Servicio Geológico Mexicano (sGM) (2019). Anuario estadístico de la minería mexicana, 2018 (Edición 2019). Servicio Geológico Mexicano. https://bit. ly/2VECtb7

(2020). Sistema Integral sobre Economía Minera (sINEm). Precio Internacional de los metales. https://bit.ly/3omhYfN

Svampa, M. (2019). Las fronteras del neoextractivismo en América Latina. Conflictos socioambientales, giro ecoterritorial y nuevas dependencias. CALAS. https://bit.ly/2VGbXOA

Téllez, I. (2019, 13 de noviembre). Industrias Peñoles: entre el acaparamiento del subsuelo y la capitalización bursátil. Ponencia presentada en el XV Coloquio de Doctorandos en Geografía, México.

(2020). La vigencia del concepto de acumulación originaria de capital en el siglo xxi. Aportaciones desde México. Pacarina del Sur, (42). http:// pacarinadelsur.com/home/abordajes-y-contiendas/1826-la-vigencia-delconcepto-de-acumulacion-originaria-de-capital-en-el-siglo-xxi-aportaciones-desde-mexico

Téllez, I. y Sánchez, M. T. (2018). La expansión territorial de la minería mexicana durante el periodo 2000-2017. Una lectura desde el caso del estado de Morelos. Investigaciones Geográficas, (96). https://doi.org/10.14350/ rig. 59607

Transparencia Mexicana (2020). Riesgos de corrupción en el otorgamiento de concesiones mineras en México. Transparencia Mexicana. 
Urías, H. (1980). ¿Quién controla la minería mexicana? Comercio Exterior, 9(30). http://revistas.bancomext.gob.mx/rce/magazines/423/3/RCE3.pdf Verbruggea, B. y Geenen, S. (2019). The gold commodity frontier: A fresh perspective on change and diversity in the global gold mining economy. The Extractive Industries and Society, 6(2). https://doi.org/10.1016/j.exis. 2018.10.014 
